\title{
PHOTOESSAY
}

\section{Buried in debt only to have their loved ones get a burial}

\begin{abstract}
The photoessay Healing The Wounds From the Drug War was compiled on the trail of people's lives that have been disrupted by this brutal campaign in the Philippines. It featured what happens to those people left behind after the killings. Some who survive end up in decrepit jails. The families of the dead, mostly from the poor who get by in hand-to-mouth existence, end up buried in debt only to have their loved ones get a burial. But it is also a story of hope for those given a new lease of life by organisations willing to assist in the rehabilitation of drug addicts.
\end{abstract}

Keywords: Duterte's war on drugs, extrajudicial killings, photojournalism, reality, rehabilitation, visual language

\section{FERNANDO G. SEPE JR}

ABS-CBN Multimedia Team

JOINED the 'nightshift' midway into the first year of the war on drugs in the Philippines. By then, hundreds of foreign journalists had descended on Manila to cover the 'hottest' story coming out of Asia. By then also, hundreds of publications had treated the story from the point of view of the photojournalists covering the campaign.

It was an easy decision to make. The photojournalists covering the war on drugs drove head on into the subject, first because it was an assignment that was dominating the headlines. Second, the story lent itself naturally to the visual language, with the blood and gore unable to translate itself other than in a medium that can capture reality while at the same time show empathy for the subject. It was akin to photographing a real war, where the medium has been proven by history to rouse the empathy of the viewer. But it was also the photographers who chose to stick to the story, even after the blood on the pavement has been cleared and the crowds have dispersed. The photojournalists chose to do this to be able to follow through to the victims, and to see how their lives are being changed by 
this unimaginable circumstance, and this is the third and most compelling reason.

What shaped the story I did later. Healing The Wounds From the Drug War, was the trail of people's lives that have been disrupted by this brutal campaign. It was about what happens to those people left behind after the killings. Some who survive end up in decrepit jails. The families of the dead, mostly from the poor who get by in hand-to-mouth existence, end up buried in debt only to have their loved ones get a burial. But it is also a story of hope for those given a new lease of life by organisations willing to assist in the rehabilitation of drug addicts.

\section{Reference}

Sepe Jr, F. G. (2017). Healing the wounds from the drug war. ABS-CBN. Retrieved from http://news.abs-cbn.com/specials/healing-drug-war

Fernando G. Sepe Jr is the head of the multimedia team of ABS-CBN's news website and previously worked for the Associated Press, as photographer, video journalist and eventually senior producer for TV documenting global events such as Hurricane Katrina in the US, the civil unrest in Myanmar, the 2004 Indian Ocean tsunami, and the 2006 World Cup in Germany. In 2018, he topped the excellence in feature writing category of the Society of Publishers in Asia (SOPA) Awards for his photoessay on the Philippine government's war on drugs. 


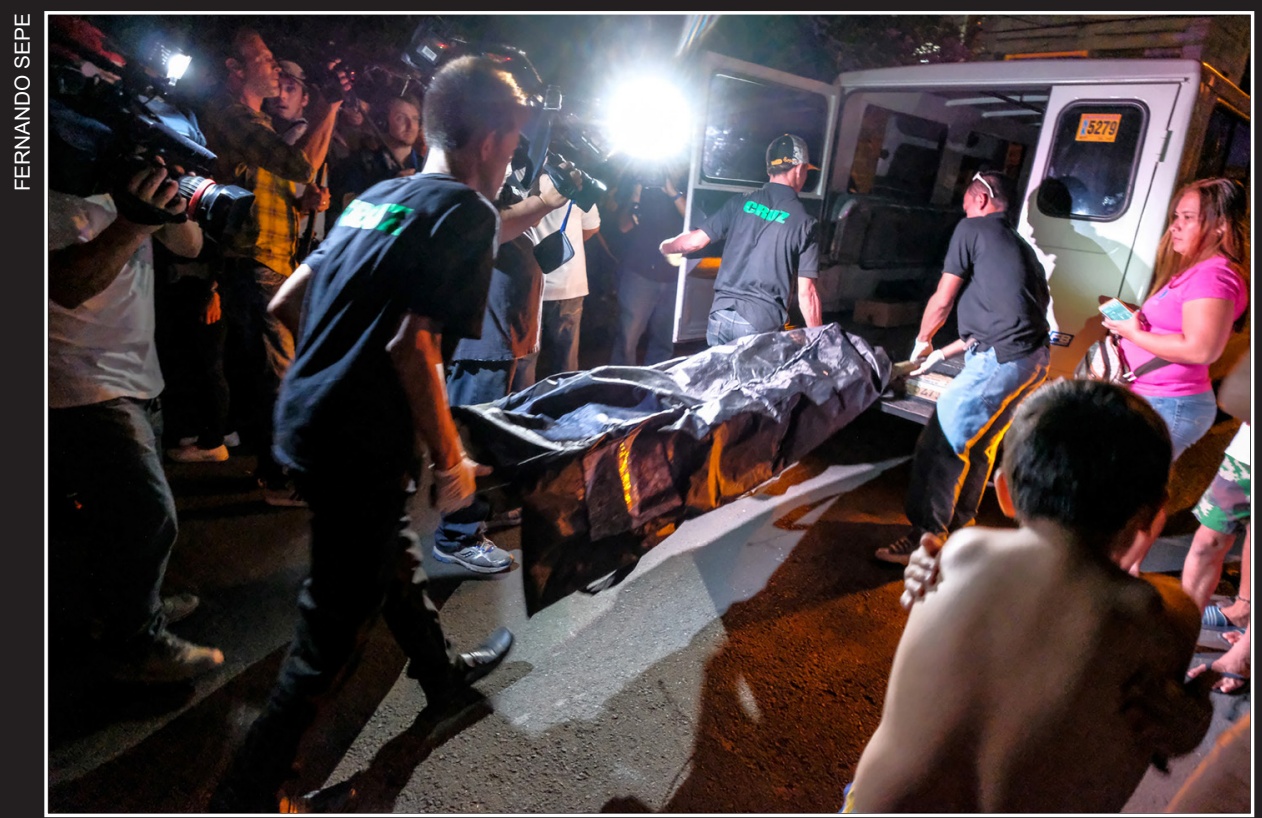

Figure 1: The body of a victim of extrajudicial killing in the Philippines is loaded into a funeral service van after being discovered on a sidestreet in Manila. 14 January 2017. 


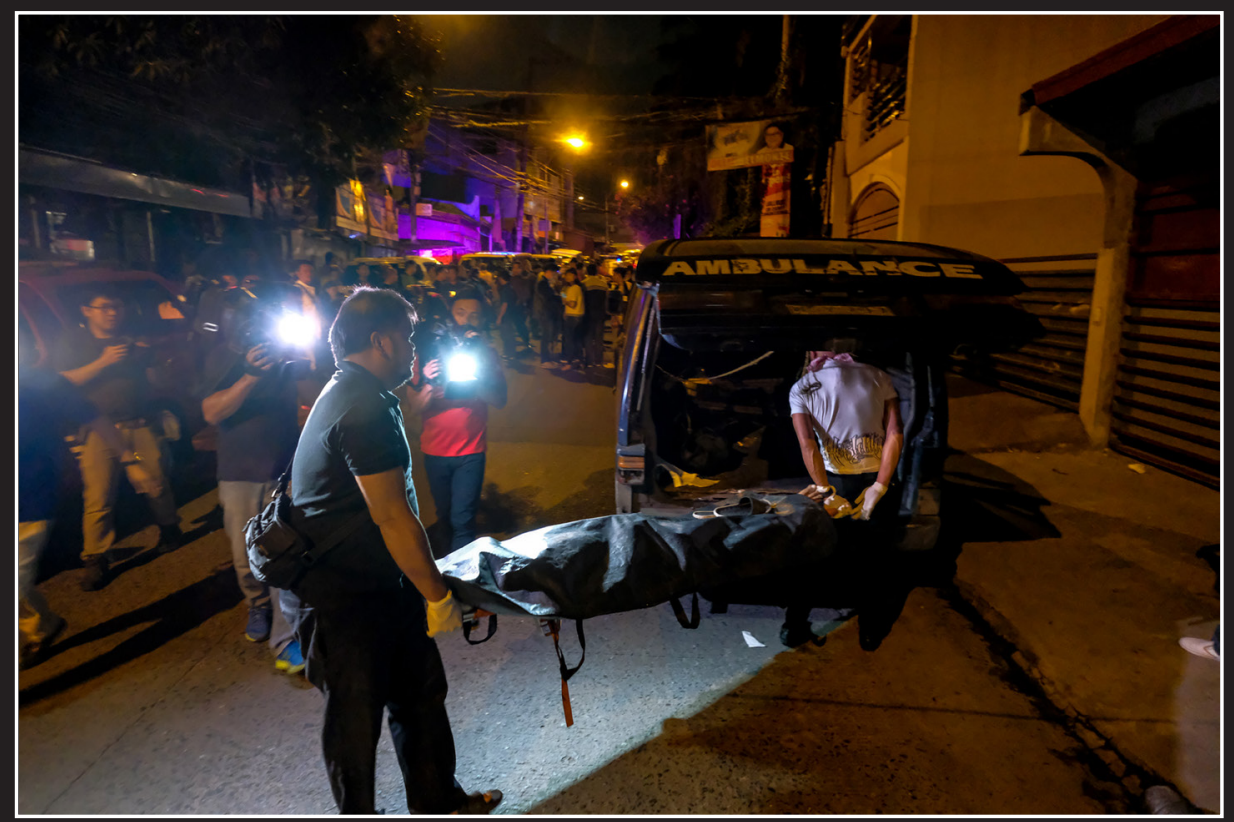

Figure 2: Journalists chase after a body recovered from a crime scene for one of the casualties of Philippine President Rodrigo Duterte's bloody war on drugs. 17 January 2017. 


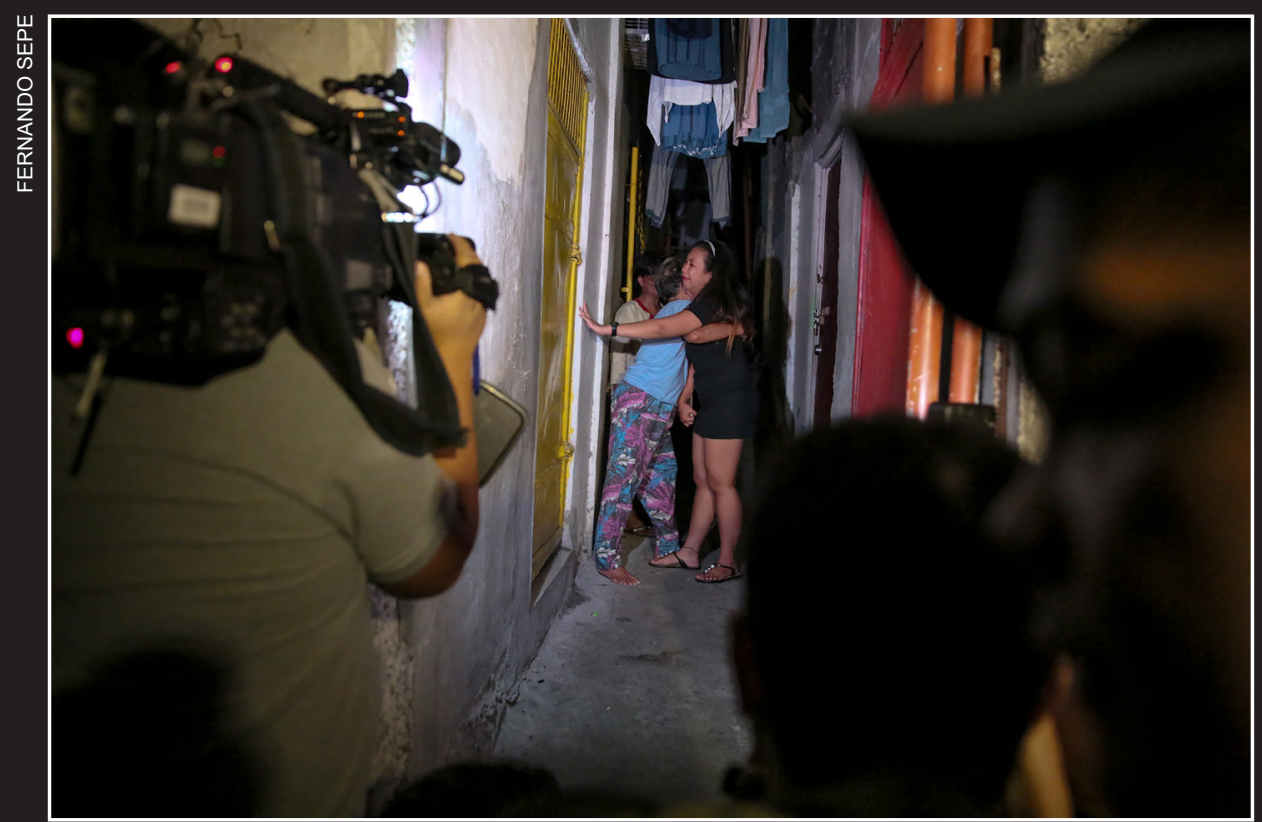

Figure 3: A relative of one of the casualties of the Philippine government's war on drugs weeps as she sees her partner dead inside their home in Manila. 17 January 2017. 


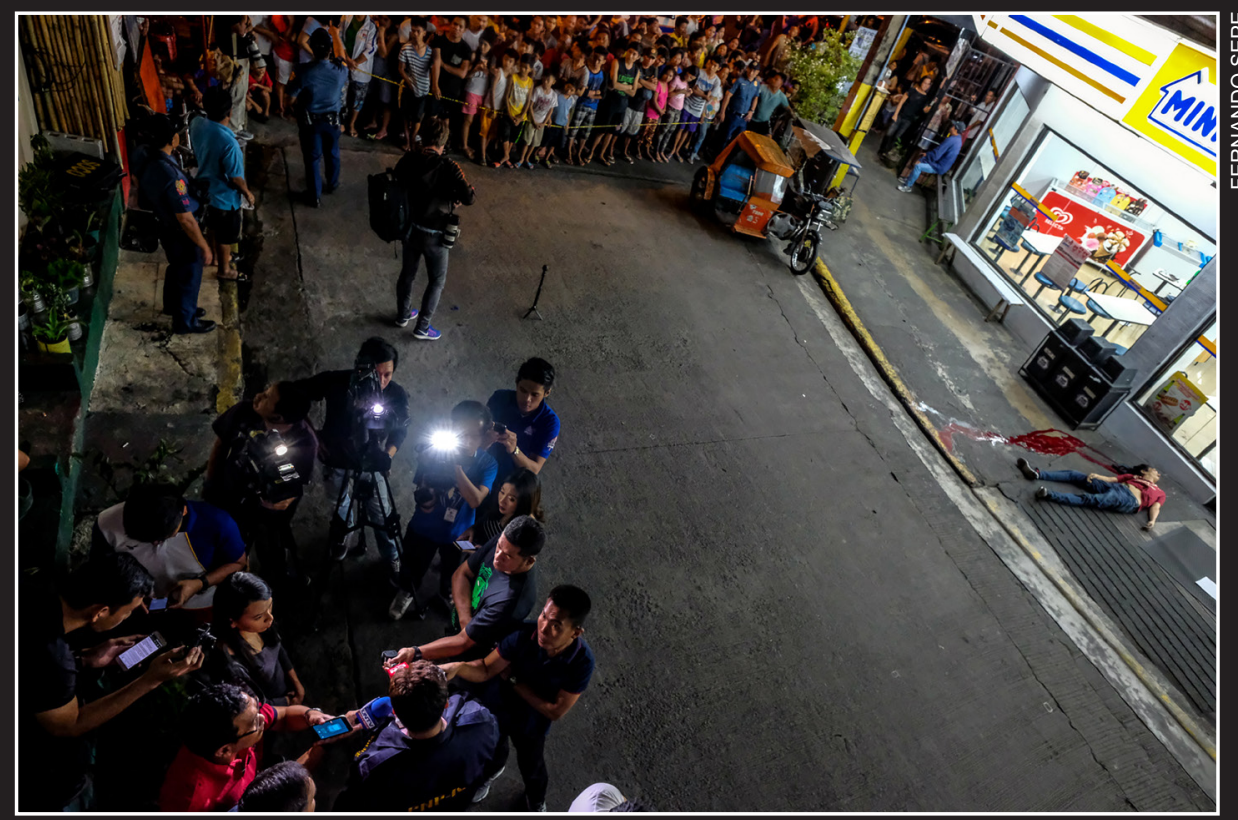

Figure 4: Media people interview police after a police operation resulted in the death of an alleged criminal on a busy street corner in Manila. 18 January 2017. 


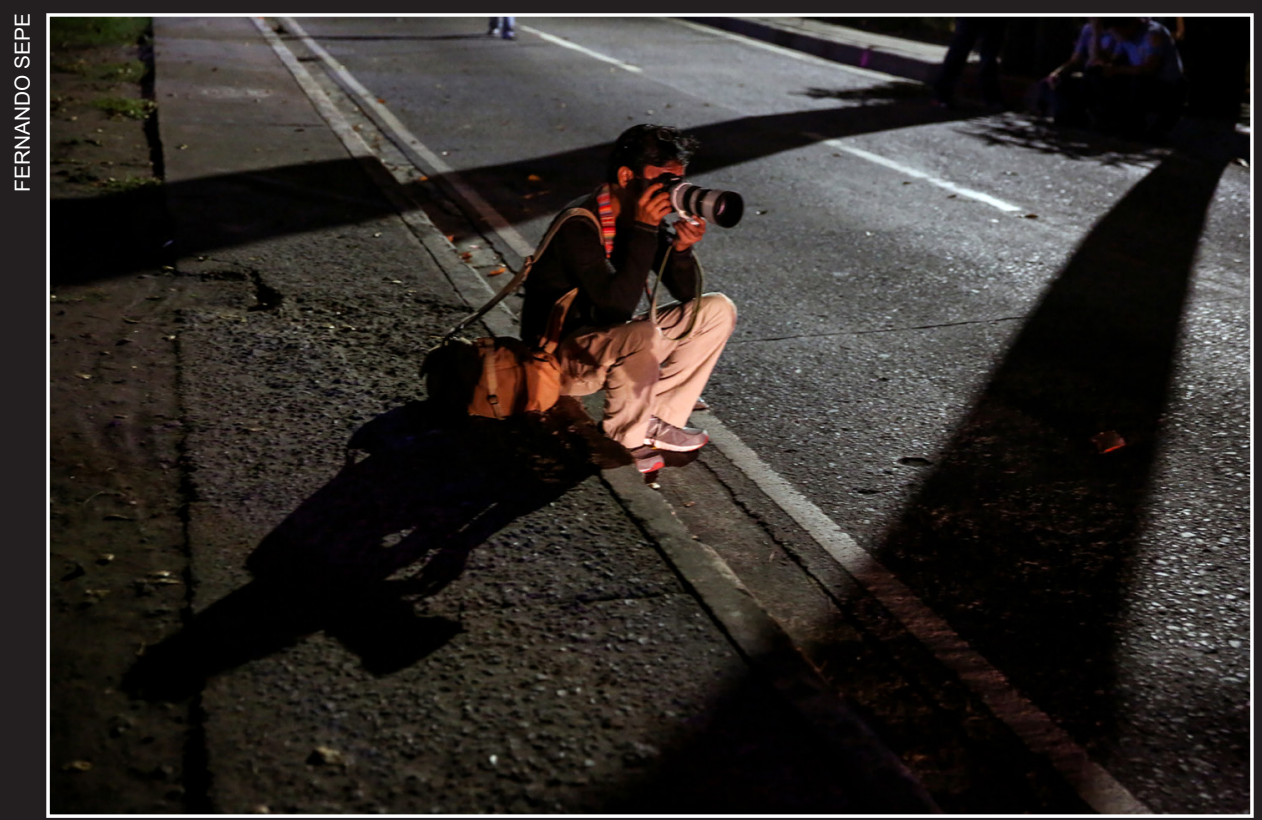

Figure 5: Brother Ciriaco Santiago, one of the nightshift photographers covering the Philippine government's brutal war on drugs, in one of the crime scenes. 8 February 2017. 


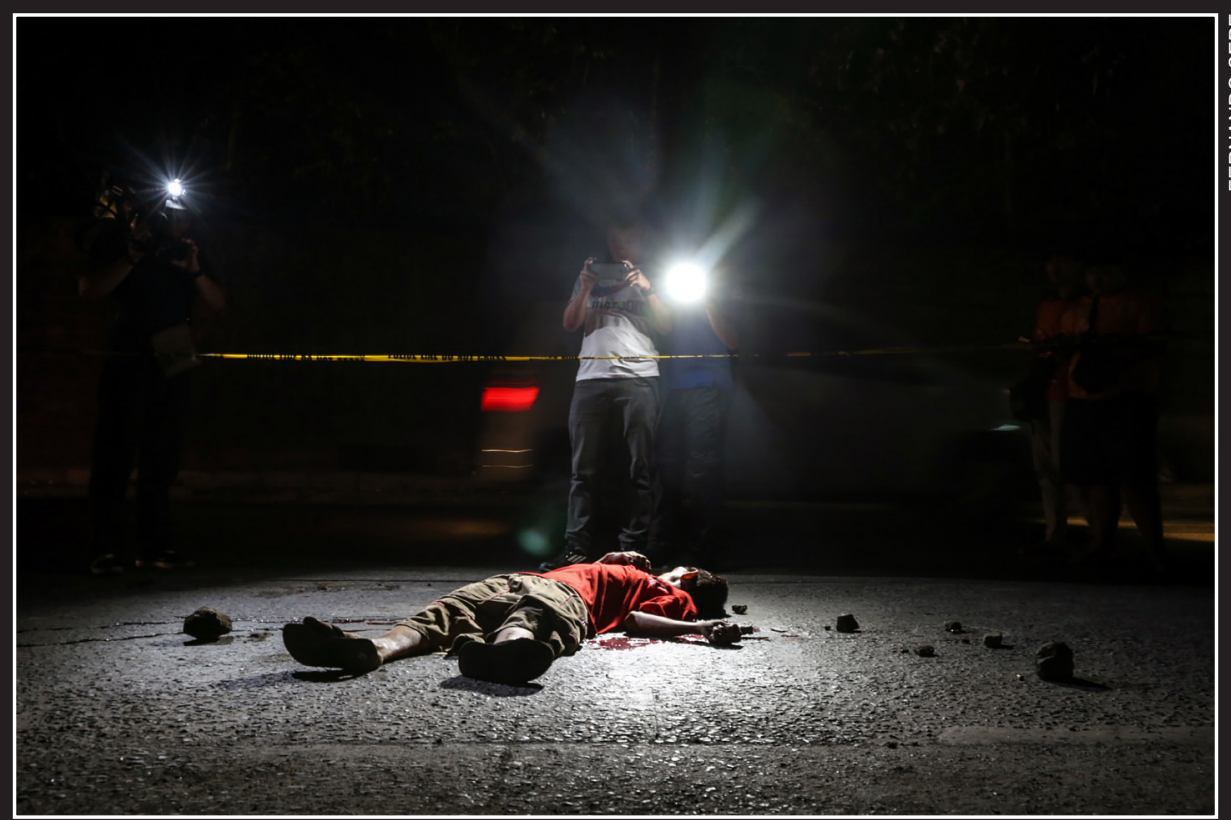

Figure 6: Journalists take photos of a body discovered by a roadside near a garbage dumpsite in suburban Quezon City, Philippines. 10 February 2017. 


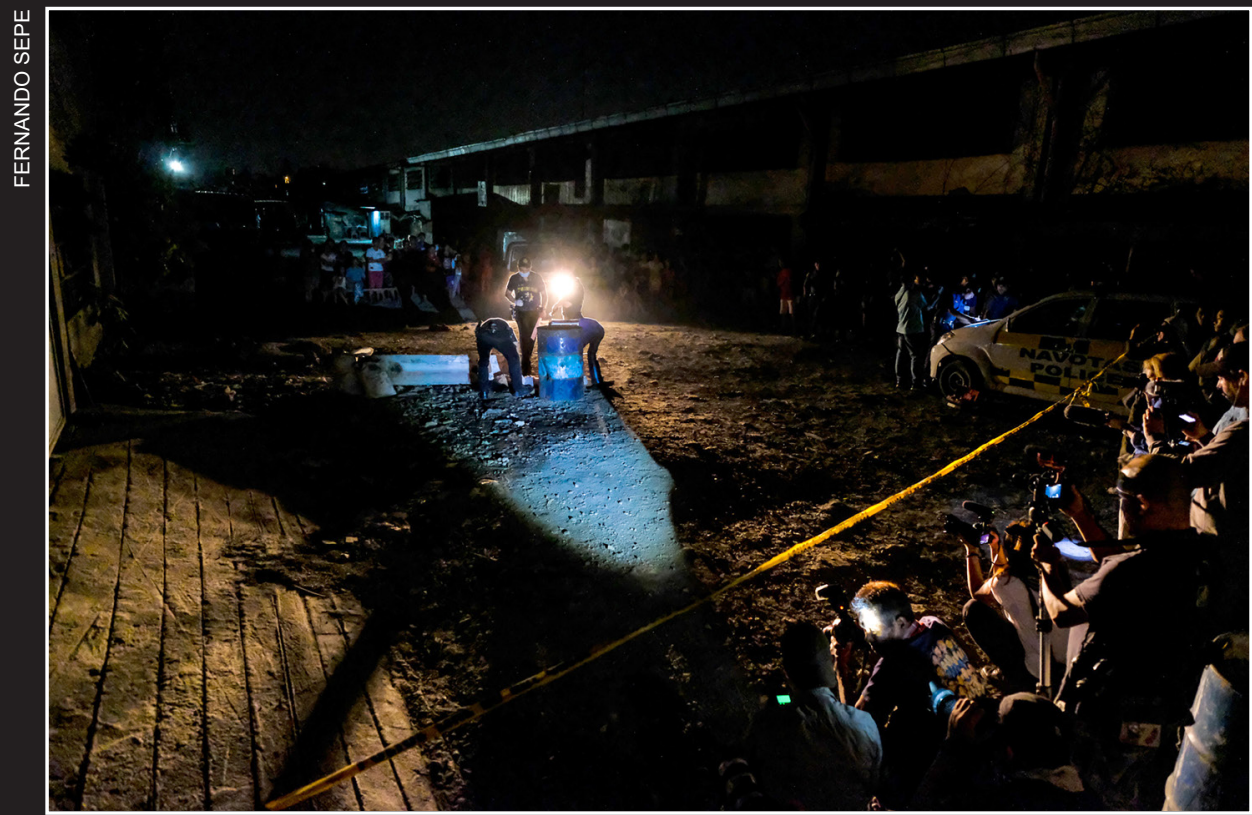

Figure 7: Journalists stay behind the crime scene tape as crime scene investigators work on the scene of an apparent extrajudicial killing in Manila. 20 March 2017. 


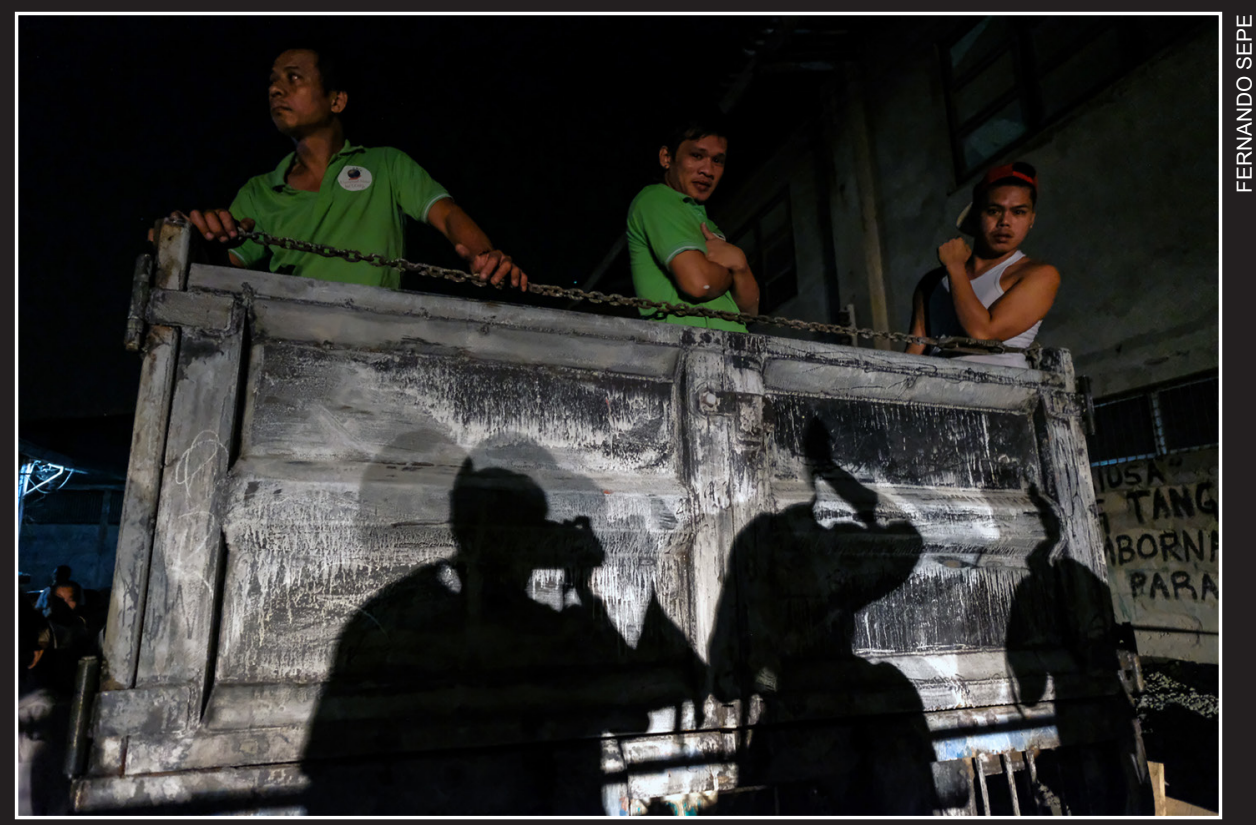

Figure 8: Journalists cover the scene of an apparent extrajudicial killing in Manila. 20 March 2017. 


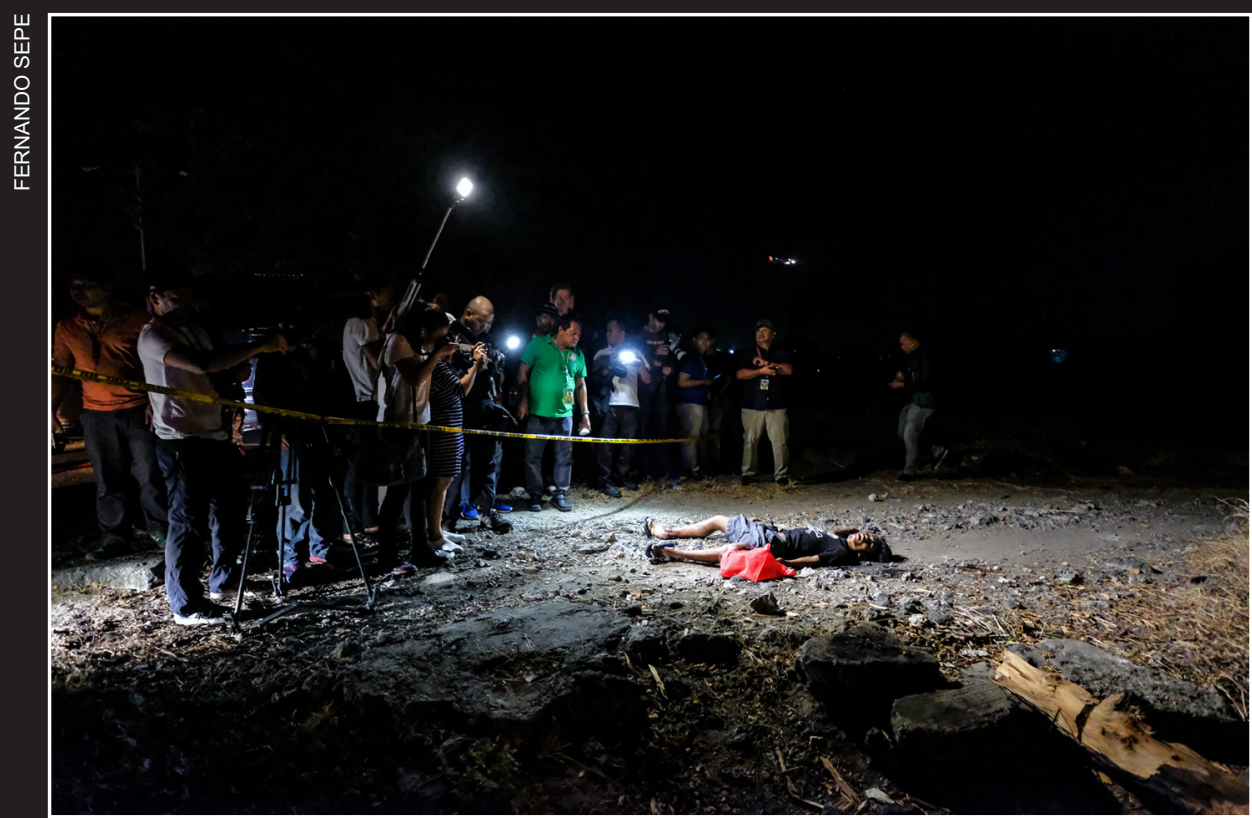

Figure 9: The Philippine media cover the killings related to Philippine President Rodrigo Duterte's war on drugs. 21 March 2017. 


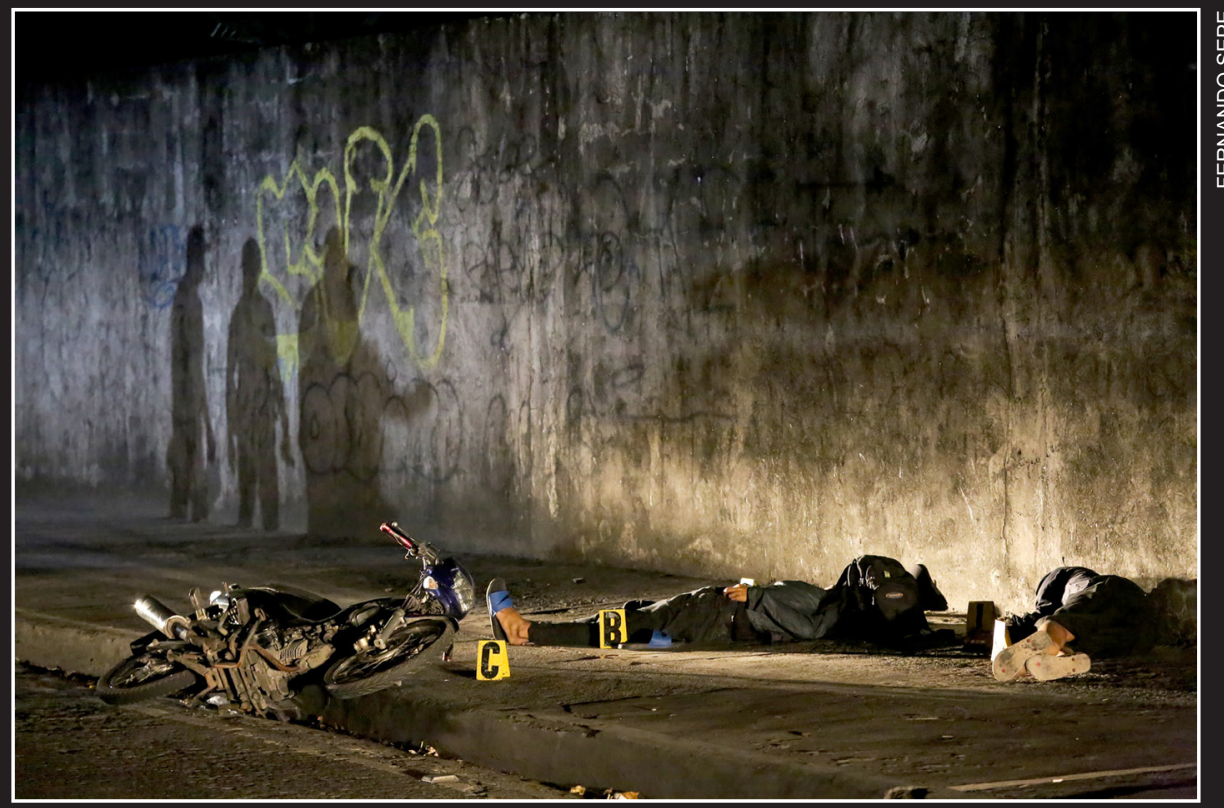

Figure 10: Bodies are discovered almost every night in the streets of Metro Manila as the Philippine government's brutal war on drugs continue in its second year. 2017. 